\title{
A Formal Total Synthesis of (-)-Brevisamide
}

\author{
Amos B. Smith III", Noriki Kutsumura, and Justin Potuzak \\ Department of Chemistry, Monell Chemical Senses Center, and Laboratory for Research on the \\ Structure of Matter, The University of Pennsylvania, Philadelphia, PA 19104, USA
}

\begin{abstract}
A formal total synthesis of (-)-brevisamide has been achieved. The synthetic approach highlights a chemoselective asymmetric dihydroxylation and a one-pot Fraser-Reid epoxidation/PMB protection reaction sequence.
\end{abstract}

\section{Keywords}

brevisamide; asymmetric dihydroxylation; one-pot; Fraser-Reid epoxidation; formal total synthesis

\begin{abstract}
Dinoflagellates, known to produce cyclic polyether toxins such as the brevetoxins A and B, ciguatoxins, and maitotoxin, ${ }^{1}$ have attracted significant interest in the scientific communities since the first isolation and structural elucidation of the brevetoxins from Karenia brevis in the early 1980 's, due to the significant toxicity and ecological ramifications of the toxins produced. More recently a related ladder-frame polyether, (-)-brevenal (1), was reported in 2005 to arise from the same species, that proved to be an antagonist of the sodium channel blocking ability of the brevetoxins. ${ }^{\text {lc }}$ This report was quickly followed in 2008 by the Wright et al. disclosure of a cyclic ether alkaloid, termed (-)-brevisamide (2), from the same red tide dinoflagellate (Scheme 1). ${ }^{2}$ Due to the structural similarity to the western portion of 1, Wright and co- workers reasoned that (-)-brevisamide (2) may prove useful in defining the biosynthetic origin of the fused polyether class of dinoflagellate toxins.
\end{abstract}

Not surprisingly, the synthetic community quickly took up the synthetic challenge of (-)brevisamide (2), and in 2009 Tachibana laboratory recorded the first total synthesis that comprised a linear sequence of 21 steps from commercially available starting materials. ${ }^{3}$ The highlight of their synthetic venture entailed the use of a Suzuki-Miyaura reaction to achieve union between a dienol sidechain $\mathbf{3}$ and an advanced ether tetrahydropyran fragment (+)-4 (Scheme 1). More recently, three additional total syntheses of (-)-brevisamide have been reported. ${ }^{4}$ From our perspective an improved strategy, taking advantage of the Tachibana Suzuki-Miyaura union, would entail the development of a more concise approach to the requisite tetra-substituted tetrahydropyran ring. In this letter, we disclose a synthetic sequence that produced the TBS-protected polysubstituted tetrahydropyran core (+)-4 in 14 steps (longest linear sequence) with an overall yield of $8.8 \%$ from the known starting material (-)-5, thus constituting a formal total synthesis of (-)-2.

We began the formal synthesis of (-)-brevisamide (2) with known alcohol (-)-5, available in one step from acrolein exploiting the Evans syn-aldol protocol..$^{5}$ Protection of the hydroxyl group as a TIPS ether (Scheme 2), followed by reductive-removal of the auxiliary

(C) 2011 Elsevier Science. All rights reserved.

*Corresponding author. Tel.: +1-215-898-4860; fax: +1-215-898-5129; smithab@ sas.upenn.edu. 
provided alcohol (-)-6 in excellent yield. Conversion to the corresponding nitrile (-)-7 via an intermediate iodide next proceeded in $96 \%$ yield, which was then reduced with DIBAL-H and in turn subjected to Wittig olefination with $\mathbf{8}$ to furnish the desired $E$-diene (-)-9 as the major product $(E: Z=14: 1)$.

Our synthetic strategy next called for a chemoselective asymmetric dihydroxylation of $\alpha, \beta$ olefin in diene (-)-9. In general dihydroxylations employing $\mathrm{OsO}_{4}$ of substrates containing both an $\alpha, \beta$-unsaturated olefin and a terminal double bond predominate at the terminal olefin. A careful search of the litereature however revealed a 2003 report by Greeves and coworkers that this chemoselectivity can be inverted by employing the $\mathrm{K}_{2} \mathrm{OsO}_{4} \cdot 2 \mathrm{H}_{2} \mathrm{O}$, when the terminal olefin possesses an adjacent bulky substituent. ${ }^{7}$ Gratifyingly, after careful adjustment of the reaction conditions (Table 1), Sharpless dihydroxylation of (-)-9 employing $\mathrm{K}_{2} \mathrm{OsO}_{4} \cdot 2 \mathrm{H}_{2} \mathrm{O}(0.5 \mathrm{~mol} \%)$ proceeded at the $\alpha, \beta$-olefin, presumably a direct result of OTIPS ether allylic to the terminal olefin. Complete chemoselectivity with excellent diastereoselectivity (15: 1; Table 1) was eventually achieved! Assignment of the diol stereogenicity was based on Sharpless precedent. ${ }^{8}$

Following the chemo- and stereoselective Sharpless asymmetric dihydroxylation, the resulting diol (-)-10 $\boldsymbol{\alpha}$ was reduced with $\mathrm{LiBH}_{4}$ to furnish triol (-)-11. We then turned to the Fraser-Reid epoxide protocol to install the terminal epoxide on the triol. ${ }^{9}$ Initially this reaction proved unsuccessful (Scheme 3). For example, use of multiple equivalents of 2,4,6triisopropyl-benzenesulfonyl imidazole (TPS-Imid) led to formation of (+)-12a, possessing a TPS group on the C11-hydroxyl, while use of one equivalent generated 12b, which unfortunately proved unstable during the workup. Equally problematic, removal of the TIPS group from (+)-12a, followed by the cyclization employing $1 \mathrm{~N} \mathrm{HCl}$, led to what we tentatively assigned $\left({ }^{1} \mathrm{H}\right.$ NMR) as the five-membered tetrahydrofuran 13 , not to the required six-membered ring tetrahydropyran 14.

Consistent with the structure $\mathbf{1 3}$ would be nucleophilic attack of water on the alkyl oxonium intermediate ${ }^{10}$ generated by the ring opening of the epoxide by the oxygen atom of the tetrahydrofuran ring (Scheme 4).

Eventually, after considerable experimentation, we discovered that when one equivalent of TPS-Imid was employed, followed by the addition of three equivalents of PMBBr, epoxide $(-)-12 c$ could be isolated in good yield in a single operation (Scheme 5). Removal of the TIPS group using tetrabutylammonium fluoride then provided (-)-15, substrate for the key cyclization event (Scheme 4). Pleasingly, treatment of (-)-15 with CSA in $\mathrm{CH}_{2} \mathrm{Cl}_{2}$ furnished the desired tetrahydropyran $\mathbf{1 6}$ which without purification was treated first with $\mathrm{PPh}_{3}$ and DPPA, and in turn with DIAD to furnish azide (+)-17 in $85 \%$ yield for the three steps. Reduction of (+)-17 employing $\mathrm{PPh}_{3}$ followed by acetylation then proceeded smoothly to furnish the advanced tetrahydropyran (+)-18. In parallel, known synthetic intermediate ( + - $\mathbf{4}$ was also prepared from the azide ( + -17 by a three-step conversion: (a) DDQ, buffer/ $\mathrm{CH}_{2} \mathrm{Cl}_{2}$; (b) TBSOTf, 2,6-lutidine $/ \mathrm{CH}_{2} \mathrm{Cl}_{2}$; (c) $\mathrm{PPh}_{3} / \mathrm{THF}-\mathrm{H}_{2} \mathrm{O}$ followed by $\mathrm{Ac}_{2} \mathrm{O}$, pyridine. The spectroscopic and chiroptical properties of (+)-4 were identical to those reported by Tachibana et al. ${ }^{3 \mathrm{a}}$

In summary, an effective synthesis of (+)-4 completes a formal total synthesis of (-)brevisamide (2). Highlights of the tetrahydopyran ring synthesis [cf. (+)-17] include a chemoselective Sharpless asymmetric dihydroxylation and a one-pot Fraser-Reid epoxidation/PMB protection reaction sequence.

\section{Supplementary Material}

Refer to Web version on PubMed Central for supplementary material. 


\section{Acknowledgments}

Support for this research was provided by the National Institutes of Health (Institute of General Medical Sciences) through grant GM-29028 and a Postdoctoral Fellowship to NK from the Uehara Memorial Foundation.

This Tetrahedron Letter is dedicated to Professor Harry H. Wasserman, scientist/scholar extraordinaire, long term editor/mentor and friend on the occasion of his $90^{\text {th }}$ birthday. Harry thank you for all you have done for the chemical/scientific community.

\section{References}

1. (a) Lin YY, Risk M, Ray SM, Van Engen D, Clardy J, Golik J, James JC, Nakanishi K. J Am Chem Soc. 1981; 103:6773-6775.(b) Shimizu Y, Chou HN, Bando H, Van Duyne G, Clardy J. J Am Chem Soc. 1986; 108:514-515.(c) Bourdelais AJ, Jacocks HM, Wright JCL, Bigwarfe PM Jr, Baden DG. J Nat Prod. 2005; 68:2-6. [PubMed: 15679307] (d) Baden DG, Bourdelais AJ, Jacocks HM, Michelliza S, Naar J. Env Health Persp. 2005; 113:621-625.

2. Satake M, Bourdelais AJ, Van Wagoner RM, Baden DG, Wright JLC. Org Lett. 2008; 10:34653468. [PubMed: 18646771]

3. (a) Kuranaga T, Shirai T, Baden DG, Wright JLC, Satake M, Tachibana K. Org Lett. 2009; 11:217220. [PubMed: 19067558] (b) Shirai T, Kuranaga T, Wright JLC, Baden DG, Satake M, Tachibana K. Tetrahedron Lett. 2010; 51:1394-1396.(c) Tsutsumi R, Kuranaga T, Wright JLC, Baden DG, Ito E, Satake M, Tachibana K. Tetrahedron. 2010; 66:6775-6782.

4. (a) Fadeyi OO, Lindsley CW. Org Lett. 2009; 11:3950-3952. [PubMed: 19639953] (b) Ghosh AK, Li J. Org Lett. 2009; 11:4164-4167. [PubMed: 19694486] (c) Lee J, Panek JS. Org Lett. 2009; 11:4390-4393. [PubMed: 19736917]

5. Gebauer J, Arseniyadis S, Cossy J. Org Lett. 2007; 9:3425-3427. [PubMed: 17637033]

6. Francais A, Bedel O, Haudrechy A. Tetrahedron. 2008; 64:2495-2524.

7. Greeves N, Lee WM, McLachlan SP, Oakes GH, Purdie M, Bickley JF. Tetrahedron Lett. 2003; 44:9035-9038.

8. Sharpless KB, Amberg W, Bennani YL, Crispino GA, Hartung J, Jeong KS, Kwong HL, Morikawa K, Wang ZM, Xu DQ, Zhang XL. J Org Chem. 1992; 57:2768-2771.

9. (a) Hicks DR, Fraser-Reid B. Synthesis. 1974; 3:203.(b) Corey EJ, Weigel LO, Chamberlin AR, Lipshutz B. J Am Chem Soc. 1980; 102:1439-1441.

10. Mascal M, Hafezi N, Toney MD. J Am Chem Soc. 2010; 132:10662-10664. [PubMed: 20681692] 


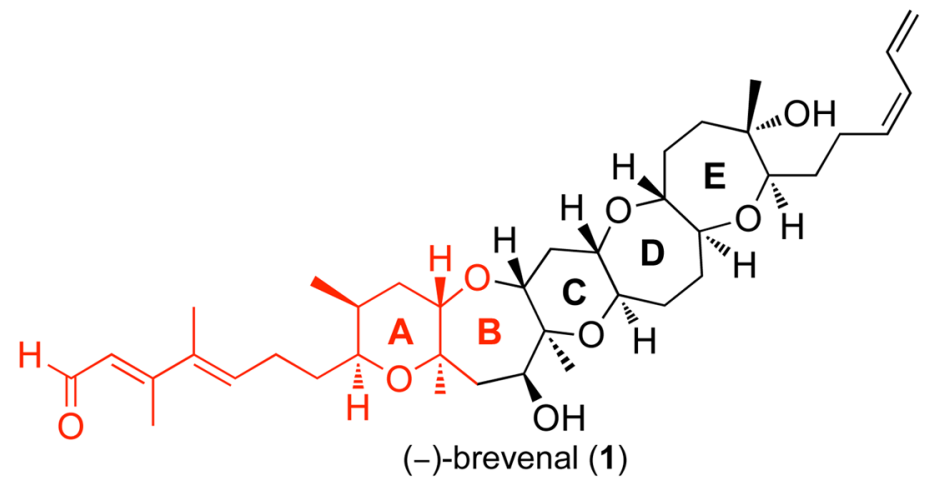<smiles>CC(=O)NC[C@H]1O[C@H](CCC=C(C)C(C)=CC=O)[C@H](C)C[C@H]1O</smiles>

1. 9-BBN, $\mathrm{Cs}_{2} \mathrm{CO}_{3}$, THF $\mathrm{PdCl}_{2}$ (dppf) $\cdot \mathrm{CH}_{2} \mathrm{Cl}_{2}$

2. TBAF, THF<smiles>CC(=C/I)/C(C)=C/CO</smiles>

3<smiles>C=C[C@H](O)[C@H](C)C(=O)N1C(=O)OC[C@H]1Br</smiles>

$(-)-5$
3. TEMPO, $\mathrm{Phl}(\mathrm{OAc})_{2}$ or $\mathrm{MnO}_{2}, \mathrm{CH}_{2} \mathrm{Cl}_{2}$

$24-35 \%$ over 3 steps ${ }^{3 a, 4 b}$<smiles>C=C[C@H]1O[C@@H](CNC(C)=O)[C@@H]([OH2+])C[C@H]1C</smiles>

$(+)-4$

known synthetic intermediate)<smiles>C1=CC=C1</smiles><smiles>C1CCCC1</smiles><smiles>C=C[C@H](O)[C@@H](C)C[C@@H](OCCC)[C@H]1CO1</smiles>

$(-)-15$

Scheme 1. 


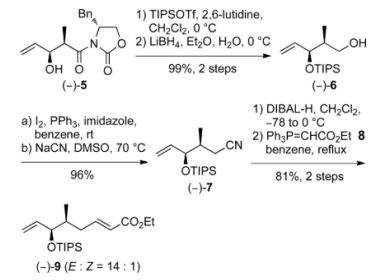

Scheme 2. 


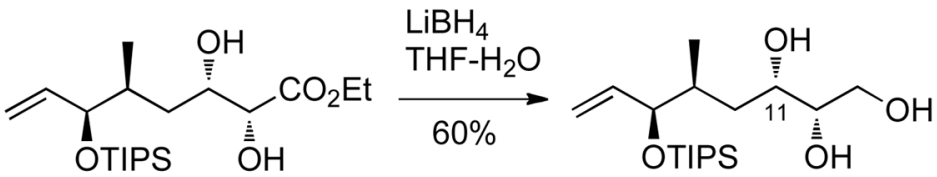

$10 \alpha$ (desired)

Tris-Imid

(excess)

$\mathrm{NaH} / \mathrm{THF}$ $99 \%$<smiles>C=CC([OH2+])C(C)CC(=C([O+])[O-])C1CO1</smiles>

$(+)-12 a$
$(-)-11$

TPS-Imid (1 equiv)

$\mathrm{NaH} / \mathrm{THF}$

a) TBAF / THF

b) $1 \mathrm{M}$. HCl aq. TPS = 2,4,6-triisopropylbenzenesulfonyl $74 \%$<smiles>C=C[C@@H]1O[C@@H]([C@@H](O)CO)C[C@H]1C</smiles><smiles>C=C[C@H]1O[C@H](CO)[C@@H](C)C[C@H]1O[SnH3]</smiles>

Not observed

Scheme 3. 


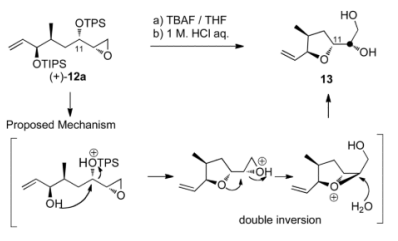

Scheme 4. 


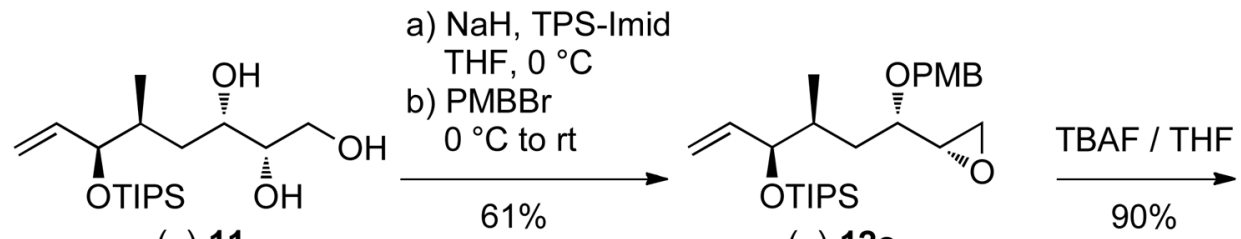

$(-)-11$

$(-)-12 c$

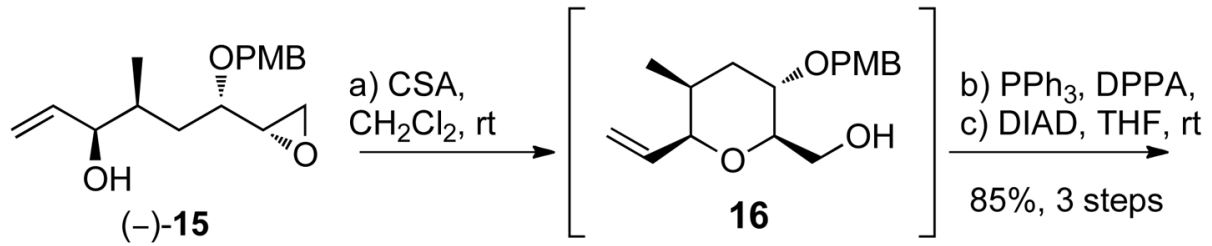<smiles>C=C[C@H]1O[C@H](CN)[C@@H](OC)C[C@H]1C</smiles>

$(+)-17$

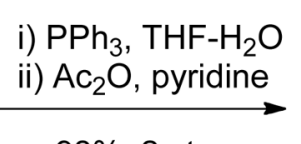

$98 \%, 2$ steps

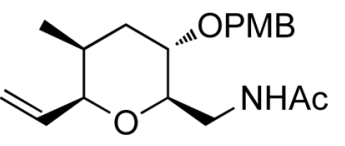

$(+)-18$

12 steps, $17.7 \%$ overall yield

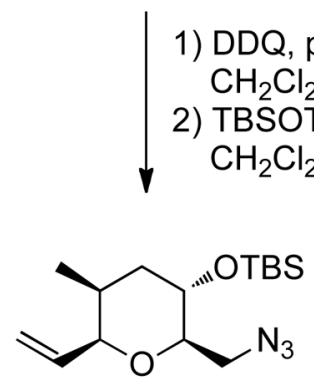

$(+)-19$

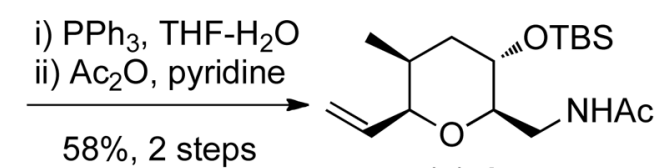

$(+)-4$

14 steps, $8.8 \%$ overall yield

(Formal Total Synthesis)

Scheme 5. 


\section{Table 1}

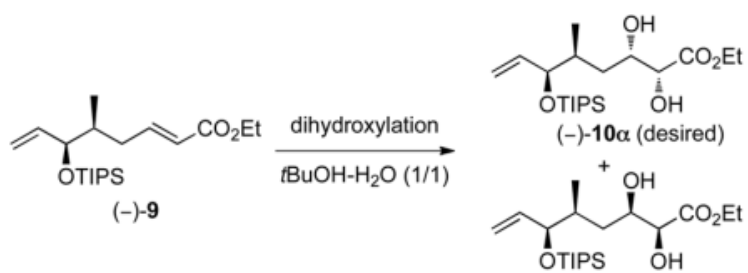

(+)-10 $\beta$ (undesired)

\begin{tabular}{|c|c|c|c|}
\hline & Conditions & Yield $(\%)$ & 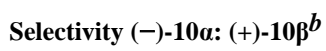 \\
\hline 1 & $\mathrm{OsO}_{4}$ in $\mathrm{H}_{2} \mathrm{O}(25 \mathrm{~mol} \%), \mathrm{NMO}^{a}, 0-10^{\circ} \mathrm{C}, 11 \mathrm{~h}$ & 51 & $1.8: 1.0$ \\
\hline 2 & AD-mix- $\alpha, \mathrm{MeSO}_{2} \mathrm{NH}_{2}, \mathrm{OsO}_{4}$ in $\mathrm{H}_{2} \mathrm{O}(25 \mathrm{~mol} \%), 0-10^{\circ} \mathrm{C}, 11 \mathrm{~h}$ & 75 & $15.5: 1.0$ \\
\hline 3 & $\mathrm{AD}-\operatorname{mix}-\beta, \mathrm{MeSO}_{2} \mathrm{NH}_{2}, \mathrm{OsO}_{4}$ in $\mathrm{H}_{2} \mathrm{O}(25 \mathrm{~mol} \%), 0-10^{\circ} \mathrm{C}, 11 \mathrm{~h}$ & 66 & 1.0: 5.8 \\
\hline 4 & AD-mix- $\alpha, \mathrm{MeSO}_{2} \mathrm{NH}_{2}, \mathrm{OsO}_{4}$ in $\mathrm{H}_{2} \mathrm{O}(5 \mathrm{~mol} \%), 0-10^{\circ} \mathrm{C}, 28 \mathrm{~h}$ & 61 & $(-)-10 a$ only \\
\hline 5 & AD-mix- $\alpha, \mathrm{MeSO}_{2} \mathrm{NH}_{2}, \mathrm{~K}_{2} \mathrm{OsO}_{4} \cdot 2 \mathrm{H}_{2} \mathrm{O}(0.5 \mathrm{~mol} \%), 0-10^{\circ} \mathrm{C}, 22 \mathrm{~h}$ & 84 & $(-)-\mathbf{1 0 a}$ only \\
\hline
\end{tabular}

${ }^{a} \mathrm{NMO}=N$-methylmorpholine $N$-oxide

$b_{\text {Determined by }}{ }^{1} \mathrm{H}-\mathrm{NMR}$ 